\title{
Специфика кодирования представлений о человеке в русских говорах Среднего Поволжья
}

\section{Specificity of Coding of Representations about the Person in Russian Dialects of the Middle Volga Region}

\author{
Татьяна Евгеньевна Баженова \\ (Самара, Россия)
}

\begin{abstract}
:
Dialect vocabulary as the artifact of the national culture should be preserved, lexical decoded, analyzed and adequately described. The current investigation involves the culturological data revealed because of the analysis of the dialect language which makes an empirical basis for the description of the peculiar features of the mentality of dialect speakers. The paper focuses on the problem of studying dialect words with its aim to analyze the language speakers. The main attention is paid to the problem of the manifestation of the speaker in the dialect word-stock. The material for the study was Russian dialects of the Samara region - one of the regions of the Middle Volga, which is widely known in the scientific literature as the intersection of cultures and languages. We can see that the thematic groups of dialect words contain a number of cultural codes, revealing the external and internal characteristics of the person, positive and negative characteristics of appearance, linguistic features, different behavior patterns in the speech of native speakers.
\end{abstract}

\section{Key words:}

Russian language; Russian folk dialects; dialectology; dialect vocabulary; Middle Volga region; the thematic group; cultural code; semantics of word; the dialect variants of the words 
В современной русистике активно разрабатывается этнолингвистический подход к анализу лексического материала народных говоров, предполагающий понимание диалектного слова как хранителя культурно-исторической информации, [TOLSTOJ 1991; BEREZOVIČ 2007; BLINOVA 2009]. Под диалектом в данном случае понимается разновидность языка на определенной территории его существования, характеризующаяся, помимо черт, свойственных всему национальному языку в целом, также некоторыми специфическими чертами.

Вопрос о взаимосвязи языка, культуры и этноса оказывается актуальным в парадигме антропоцентрических исследований, причем привлечение этнографических и культурологических данных имеет исключительное значение, так как помогает объяснить и связать воедино многие факты при описании специфических черт менталитета того или иного этноса. Главной задачей исследователей становится изучение языка с целью познания его носителя (работы Н. Д. Арутюновой [ARUTJUNOVA 1999], Т. И. Вендиной [VENDINA 2002], К. И. Демидовой [DEMIDOVA 1993, 16-21] и др.).

Неповторимый социокультурный облик русского населения Среднего Поволжья нашел отражение в местных особенностях языка, в большей мере в диалектной лексике.

Самарская область расположена в среднем течении Волги, в районе её крутого петлеобразного изгиба, называемого Самарской Лукой. Территория области разделяется Волгой на правобережную и левобережную части, при этом большая часть территории приходится на заволжскую, левобережную сторону. Регион всегда отличался разнообразием природно-климатических условий, многонациональным составом населения, активностью миграционных процессов, сложностью культурно-языкового ландшафта [DUBMAN, KABYTOV 2007, 23-25; KABYTOV 2012, 5-20; KABYTOV, DUBMAN, LEONT'JEVA $2012,7-8]$. Под влиянием этих факторов сформировался своеобразный этнический и языковой состав русского населения самарского Поволжья [JAGAFOVA 2013, 5-10]. Самарские говоры интересны с точки зрения типологии и географии диалектных особенностей, включая и особенности лексико-семантического уровня.

В тематическом словаре самарских говоров представлена большая группа слов, описывающих человека, его поведение в обществе, систему ценностей. Тематический принцип расположения материала в словаре не только позволяет наглядно представить системные отношения в лексике, но и создает условия для определения особенностей языковой сегментации действительности. Понимание слова как хранителя культурно-исторической информации в настоящее время становится важным аспектом изучения диалектной лексики. Подтверждением данного тезиса могут служить, например, исследования С. М. Беляковой 
[BELJAKOVA 2016, 27-35], Т. В. Леонтьевой [LEONTJEVA 2012, 27-43]. Изучение семантической структуры диалектного слова дает возможность выявления региональной картины мира, поскольку все компоненты значения обусловлены специфической значимостью объектов действительности, избирательным к ним отношением, образом жизни, климатом, историко-культурным ландшафтом региона.

Как известно, образ человека является средоточием системы ценностей народа. В современном русском литературном дискурсе при оценке социальных качеств человека в первую очередь оценивается вхождение человека в класс лиц с определенными характеристиками (тихоня, умница, реалист), наличие у него определенных самостоятельно существующих качеств (трусливый, полон энергии) и способность к совершению социальных действий (решительный, пассивный). Внешние характеристики, неотъемлемые атрибуты внешности занимают периферийное положение в системе социальных качеств человека [KIM 2005, 174]. Интересно проследить, как преломляется взгляд на человека внутреннего и внешнего в диалектной языковой картине мира на лексическом материале говоров определенной территории.

Рассмотрение лексики говоров по тематическим и лексико-семантическим группам предполагает не только определение семантики слов, но и выявление мотивационных признаков, положенных в основу наименований, так как одним из отличий диалектной лексики является тенденция к прозрачности внутренней формы. Исследователь, обратившийся к изучению языка культуры, неизбежно сталкивается с необходимостью культурологического объяснения отождествления человека с тем или иным явлением действительности.

Для определения специфики кодирования представления о человеке в диалектном языке применяют тематическую классификацию диалектной лексики, в рамках которых устанавливаются мотивационные связи. Система мотивационных признаков диалектных слов позволяет определить базовые образы регионально маркированного представления о человеке. Слова, содержащие эмоционально-оценочную характеристику человека, образуют в самарских говорах несколько тематических групп. В их составе наблюдаются существительные, прилагательные и глаголы, причем существительные преобладают.

\section{Характеристика человека по отношению к нормам нравственности и поведения}

Номинативные воплощения таких качеств человека, которые определяют его отношения с другими членами общества, составляют самую большую 
по численности лексическую группу. Следование нравственным нормам строго оценивается носителями говоров, например, слушли́вые, т. е. послушные, покладистые люди, воспринимаются положительно, а бесшабашное пренебрежение всеми нравственными нормами подвергается осуждению, например, лексема во́льник в самарских говорах имеет отрицательную коннотацию.

Нормой отношения человека к людям считается доброта, это качество имеет абсолютную ценность, поэтому диалектное обозначение этого качества редко сопровождается семантической дифференциацией, например: жела́нница 'заботливая женщина', забо́тный 'заботливый', жальни́вый 'жалостливый, отзывчивый', жела́нный 'внимательный, заботливый', люби́тельная 'заботливая'. Проявлять заботу о слабых и больных, то есть хетать, nокоить, ходить за кем-л., означает в наивно-языковой картине мира высшее проявление добродетели: Хожалка у меня из милосердия, она у меня убирается, за мной ходит, желанная, внимательная (с. Мосты Пестравского р-на). Быть добрым естественное, само собой разумеющееся качество человека, и отсутствие его лексически маркируется носителями диалекта, ср.: Хороший человек так и есть хороший, а если злой, то злюга (с. Мосты Пестравского р-на). Злой человек (врагу́ша, ляди́на) оценивается носителями традиционной культуры как противник, враг, расшатывающий привычный уклад жизни. Ср.: ляд 'нечистый, черт' [FASMER 1986b, 549]; ляд возьми 'черт возьми' Ставроп. Самар. [MYZNIKOV, KUZNECOVA 1981, 259].

Качества, мешающие поддерживать гармоничные отношения в обществе, часто имеют в самарских говорах детализированное лексическое обозначение и выделяются разнообразием отрицательной оценки: жуля́бия/ /жуля́бий 'проныра, хитрец, обманщик', неотёс 'грубый, невежливый человек', доку́чница 'надоедливая женщина', зави́дчик, зави́дник/зави́дница 'завистник', чва́нец/чва́нка 'гордый человек', выки́дывка 'гордячка, зазнайка', подма́зчивый 'льстивый', назо́листый 'надоедливый', неприи́мчивый 'неприветливый' и т. д. Широко распространены в самарских говорах эмоционально-оценочные наименования таких отрицательных качеств человека, как жадность (жаду́ля, промазни́чка, жадо́бный), распутство (приблюдник, потаску́ня, верту́шка, шля́лка, шальі́га), пьянство (байгу́ш, попиво́ха, лотрьі́а, лупя́тка). В маркировании тех или иных негативных характеристик человека в данной тематической группе прослеживается избирательность, что позволяет определить систему ценностей носителей диалекта. Отклонение от нормы в характеристике человека вербализованы в определенных сценариях поведения, например, пьянство, распутство, безделье и бедность зачастую взаимно детерминированы. 
Собирательное, обобщенное обозначение отрицательных качеств человека вербализуется единичными лексемами, например: вахло́ 'плохой человек, дрянь'.

В данной тематической группе преобладает акциональный код характеристики человека, то есть способность к совершению социально значимых действий: слу́шаться - слушли́вый, докуча́ть - доку́чница, ходить за кем-л. хожа́лка, зави́довать - зави́дчик, попива́ть - попиво́ха и т. п. В качестве мотивирующей основы могут выступать диалектные слова, ср.: хаба́льный 'грубый, невежливый' - хаба́лить 'ругаться, буянить, озорничать' [FASMER 1986с, 213]; шальі́га 'распутный человек' - шала́ться 'ходить без дела, распутничать'. Реже используется предметный код, например: лупя́тка 'женщина-пьяница' ло́nоть 'плохая, бедная, рваная одежда' [MYZNIKOV, KUZNECOVA 1981, $141-142]$.

Для лексики самарских говоров по теме «Человек» характерны и семантически переосмысленные заимствованные слова, ср.: тюркизм байгу́ш 'пьяница' из тат., узб. baiyuš ‘бедняк', казах. baiyus ‘жалкий, бедный’ [FASMER 1986a, 107].

\section{Общительность, разговорчивость, особенности языка и речи}

В народном мироощущении репрезентируются такие социально значимые качества человека, как разговорчивость, общительность, способность говорить внятно. Люди, способные находить общий язык и поддерживать беседу со всеми, получают положительную характеристику, например: бахо́ря 'любительница поговорить'; москва́ 'о ребенке: разговорчивый, словоохотливый'; баля́сник/баля́сница, щелку́н - 'разговорчивый, словоохотливый человек'; басли́вый, ба́ский, брехли́выц̆, брешли́вый - 'разговорчивый'; шо́борский, пова́дливыци - 'общительный'. Словоохотливость является достоинством человека, но иногда граничит с пустословием и многословием, которые считаются недостатком: Балясник, много говорит, да не по делу (п. Сокский Исаклинского p-на) и т. п. Показательно, что словами балабо́н, балабо́лить, балабо́нить могут характеризоваться и красноречивые люди, и пустословы, болтуны. В народном представлении разговорчивость не должна отвлекать человека от основных занятий, она должна проявляться уместно. Отвлекает слушателя и необычная манера говорить, при этом отрицательно оценивается речь невнятная, замедленная или чересчур быстрая: борбота́mb, бунча́mь, вя́кать 'говорить невнятно', вяку́ша 'человек, который медленно говорит', частоба́й 'человек, который говорит много и быстро'.

В диалектном языке обычно отрицательно воспринимается речь непонятная и незнакомая (лопота́mb, бормота́mb), обусловленная незнанием или плохим 
знанием языков. Так же по-разному оценивается привычная речь местных, сро́дошних, жителей и речь чужих, стра́нних, людей. Стра́нние люди чаще всего бормя́m, варня́кают, каля́кают, ср.: Не ходите, девки, замуж во Царевщину-сёло, не по-нашему калякают: чао́-чао́-чао́ (частушка) (с. Курумоч Волжского р-на). В таком полиэтническом и поликультурном регионе, как Среднее Поволжье, лексически маркируются даже языковые особенности русских, в речи которых сохраняются признаки различных материнских говоров: цовока́ны - люди, в речи которых есть цоканье - произношение ц вместо ч, например, в слове цаво 'чего'; баюньі - местные жители и жители окрестных сёл, употребляющие в речи слово ба́ять 'говорить'; ба́mы, ба́тки - жители соседних сел, в речи которых присутствует сильное стяжение гласных в глагольных формах, например, бат, т. е. ба́ет 'говорит'; егунь́ - жители степных сёл, произносящих в окончаниях прилагательных, местоимений и порядковых числительных ого, его, а не общепринятое ово, ево.

Таким образом, в данной тематической группе лексики самарских говоров большое количество диалектных слов выступает обозначением различных отклонений от нормы дозирования, звучания и доходчивости речи. В качестве основы образной репрезентации языка и речи, отклоняющихся от привычных норм, зачастую используются слова, образованные от звукоподражаний и междометий (бала́ндить, баля́кать, борбота́mb, бунча́mь, бурде́ть, каля́кать, ляля́кать, пустобрёхать, тара́кать и др.).

\section{Характеристика внешности человека в связи с физическими особенностями и состоянием здоровья}

Оценка внешности всегда была социально значима для сельского человека. Одним из оснований положительной характеристики человека в языковой картине мира носителей говоров является внешнее проявление физического здоровья: Молодая была пригожая да справная, хоть и есть было сроду нечего (с. Давыдовка Приволжского р-на). Лексическая группа со значением 'крепкий, здоровый человек' представлена целым рядом слов, объединенных синонимическими отношениями: живокро́выци, двоежи́льныцй, жи́листый, налито́й и др. и антонимичными им словами со значением 'физически слабый, болезненный человек’: квёльй, дря́бльй, неудобныцй, никудышныц̆, стя́бльй, до́хлядь и др.

Репрезентирует отношение к физическому здоровью человека указание значимые характеристики общей конституции, в основе которой также лежит акциональный код, основанный на сходстве внешности с обычными, повседневными действиями человека. Эталон завершенного действия (cmamb, nocmáвumb, нали́mb, уряди́ms, спра́вить и под.) лежит в основе образного обозначения 
хорошего телосложения (стани́стыцй, поста́вныци, уря́дныци - 'статный человек') и умеренной полноты (налито́й, спра́вный). Избыточность в проявлении какого-либо действия воспринимается народным сознанием отрицательно, поэтому внешними проявлениями нездоровья человека считаются избыточная полнота: раско́рмленник 'полный человек' - от раскормить, ши́рный 'полный, толстый' - от расшириться.

Реже встречается биоморфный код характеристики внешности человека, в основе которого лежат образы растений: деги́ль 'худой и высокий человек' (ср. в самарских и других русских говорах деголья́ 'ботва, длинные тонкие плети растений'; диги́ль 'длинный тонкий стебель огородного растения' [MYZNIKOV, KUZNECOVA 1972, 53]).

В общей характеристике человека носителями говоров чаще всего отмечается физический недостаток, который мешает полноценно трудиться, выполнять работу по дому, обслуживать себя: килу́н, кила́стый 'о человеке с грыжей', кондыєба 'хромой человек', неклёка 'неполноценный человек, имеющий увечья' и др. Мешают человеку быть полноценным членом общества и такие особенности внешности, как большой живот у мужчин, неуклюжесть. См. примеры: требу́стый, 'пузатый, толстый' - от требуха́; разгильдя́й/разгильдя́йка, раздолба́й м., нескладёна ж. - 'нескладный, неуклюжий человек'; культя́nыцй, каца́пьй, ульідый - 'косолапый'.

В условиях замкнутости социума, в котором веками формировался менталитет сельского жителя, наличие очевидных, даже незначительных, особенностей внешности оценивается негативно, как признак чужеродности: «Ну чо такое, чо ть забраковал?» - «На-а, девчонка, а родить будет, а ребятишки будут с красными волосами, и ех замуж нихто не возьмёт» (с. Украинка Большечерниговского р-на). Браки между жителями разных сел раньше заключались в исключительных случаях, и одной из причин при этом были физические недостатки жениха или невесты. Ср. неклёка 'неполноценный человек, имеющий увечья': Такую неклёку кто возьмёт? (с. Степное Мамыково Кошкинского р-на).

Незначительные в народно-языковом представлении особенности внешности обычно не кодируются в диалектной лексике. Если в говоре и присутствуют номинации человека высокорослого, с большими ушами и т.п., то в традиционном диалектном дискурсе они представляют собой негативные эмоционально-оценочные характеристики человека (аффектонимы), которые употребляются не всеми носителями говоров и ситуативно. 


\section{Характеристика интеллектуальных способностей человека}

Интеллектуальные способности в народно-языковой картине мира занимают одну из ведущих позиций в характеристике человека. Высокий уровень интеллекта оценивается носителями говоров всегда положительно: Господ не пехаю ['осуждаю'], они не разбро́дные, а уммственные люди были (с. Хрящевка Ставропольского р-на); Дети сейчас продумныі́, всё спросют (с. Большая Черниговка); Он (муж) не учился, а мне помогал считать, был мозголо́вый, сам дошёл (с. Александровка Большеглушицкого р-на); Он-то беда прохо́дец, больно памятливый (с. Ефремовка Богатовского р-на).

Интеллектуальная неполноценность человека в диалектном языке лексически маркируется с учетом дифференциальных признаков проявления этого недостатка. Чаще всего глупость определяется в связи с рассеянностью, невнимательностью человека: зева́ка, ротозе́я, расто́nша, тюхтя́й - все эти диалектные слова являются синонимами литературно-просторечного слова разиня. Значительная степень умственной неполноценности ассоциируется с отсутствием понимания окружающих (бельме́с 'дурак', толма́ч 'бестолковый человек') и, как причина самоизоляции человека от общества, воспринимается очень негативно.

Специфика народно-языковой оценки умственных способностей в самарских говорах проявляется в том, что кодирование характеристики интеллектуальных способностей человека является результатом образного представления его особенностей с использованием целого спектра культурных кодов. Ср. акциональный код: встря́хнутый 'со странностями' - от встряхнуть (перемешать содержимое); разбро́дный 'сумасбродный' - от разбрестись (утратить целостность, единство); предметный код в сочетании с переносом по смежности: ала́бор 'сумасшедший человек' - от ала́бор 'порядок' (отсутствие порядка в голове); засе́льщина 'недалекий, необразованный человек, человек из глуши' - от село (отсутствие широкого доступа к знаниям); биоморфный код: валуи́ 'темные, некультурные люди' - от валу́й 'название лесных грибов' (отсутствие необходимых знаний у человека, живущего в глухом месте); ре́дя ‘простоватый, глупый человек' - от ре́дька (овощ, отсутствие способностей к интеллектуальной деятельности) и т. п.

\section{Характеристика человека по его отношению к труду и собственности}

Домовитость и трудолюбие - это качества, занимающие особое место в системе ценностей сельских жителей. Трудиться на земле, иметь дом, вести хозяйство, иметь практические навыки для сельского человека так же естественно, как 
быть здоровым, соблюдать моральные нормы, жить. У хорошего хозяина всегда есть дом, ср.: домову́ха, домовни́к/домовни́ца - 'хороший хозяин', бездо́мник/бездомо́вка - 'плохой хозяин'; бездомо́вый ‘бесхозяйственный'. Наличие, недостаток или отсутствие земли в образной репрезентации отношения к хозяйствованию не учитываются, очевидно, для носителей самарских говоров это и в прошлом было неактуально, поскольку регион всегда характеризовался благоприятными природными ресурсами, способствовавшими основным занятиям сельских жителей.

В данной лексической группе богато представлена лексика, репрезентирующая отношение к тем или иным сценариям поведения человека, которые характеризуют его отношение к труду. Общеупотребительные лексемы лежать, нерадивый, непутёвыци, опрометчивый, лёгкий и диалектные слова канадо́бить, вара́кать 'работать плохо', льіндать 'ходить без дела' - являются когнитивными координатами лексической характеристики плохо работающего, ленивого, бесхозяйственного человека: лего́ша, вараку́ша - 'лентяй'; опромётка, льінда - 'лентяйка'; неради́вка, непу́тница - 'плохая, ленивая хозяйка'; уле́жливый 'ленивый'. Бедность, бездомье, жизнь за чужой счет в народном сознании носителей говоров считаются огромным несчастьем, но тем не менее подвергаются осуждению, потому что об руку с бедностью идет пренебрежение нормами жизни. В самарских говорах слова гола́х 'бедняк', кусо́чница 'нищенка', ля́да 'ленивый человек, лентяйка, лентяй', мьіканник ‘бродяга', махо́р ‘бесхозяйственный, беспутный человек', шала́бельник 'лодырь' являются аффектонимами.

\section{Выводы}

Данный в настоящей статье перечень положительных и отрицательных оценок различных сценариев поведения человека в самарских говорах может быть продолжен. Например, разнообразием отличается характеристика человека с точки зрения его склонностей и привычек поведения в быту. С этой точки зрения носителями русских говоров чаще всего оценивается чистоплотность человека: чистохо́лка 'чистоплотная женщина', замара́й, вахла́к - 'неопрятный человек', махо́р 'оборванец', заля́, разва́рза 'грязнуля'; грязнома́зый 'нечистоплотный'. Нормой эмоционального состояния и поведения человека в говорах Среднего Поволжья является веселье, жизнерадостность, отсутствие суетливости, ср. примеры: гагату́н 'веселый человек', куроле́сник 'шутник, озорник', тухарно́й ‘боевой, веселый', вертепля́с, скаку́н 'плясун'. Все перечисленные оценочные характеристики человека, воплощенные в лексике самарских говоров, позволяют реконструировать 
одобряемую в традиционной народной культуре модель поведения человека в социуме.

При формировании в народно-языковом представлении эталона поведения человека используются разнообразные культурные коды, что говорит об активном восприятии картины мира носителями говоров и о неисчерпаемости ресурсов диалектного языка. Формирование образных наименований, содержащих характеристику человека, осуществляется путем семантического переноса, основанного на сходстве и смежности. Наиболее продуктивным является акциональный код, основанный на сходстве поступков человека с привычными, регионально маркированными действиями сельских жителей Среднего Поволжья. Интерпретация культурных кодов на материале данного фрагмента диалектной лексики отражает его главное отличие от общенародной ценностной шкалы поведения человека - приоритет социально значимых действий и внешних признаков человека над всеми остальными.

\section{Благодарности}

Автор выражает признательность Отделению гуманитарных и общественных наук Российского фонда фундаментальных исследований (РФФИ) и Ассоциации вузов «Самарский региональный научно-образовательный комплекс» за поддержку научного изучения диалектной лексики. Публикация подготовлена в рамках проекта РФФИ №18-412-630004 «Диалектное слово в русских говорах самарского Поволжья».

\section{Библиография:}

ARUTJUNOVA, N. D. (1999): Logičeskij analiz jazyka: Obraz čeloveka v kul'ture i jazyke. Moskva.

BELJAKOVA, S. M. (2016): Tradicionnaja kultura i dialektnyj slovar'. In: MYZNIKOV, S. A. (red.): Slavjanskaja dialektnaja lexikografija 2: Materialy conference. St.-Peterburg, s. 27-35.

BEREZOVIČ, Je. L. (2007): Jazyk i tradicionnaja kul'tura: Ètnolingvističeskije issledovanija. Moskva.

BLINOVA, O.I. (2009): Slagajemyje narodnoj rečevoj kul'tury. Jazyk i kul'tura, 20o9, № 2 (6), s. 5-10.

DEMIDOVA, K. I. (1993): Territorial'noje var'jirovanije leksiko-semantičeskich paradigm. In: DEMIDOVA, K. I. (red.) i dr.: Slovo v sistemnych otnošenijach na raznych urovnjach jazyka. Jekaterinburg, s. 16-21. 
DUBMAN, È. L., KABYTOV,P. S. (eds) (2007): Povol'žje - “vnutrennjaja okraina” Rossii: gosudarstvo i obščestvo v osvojenii novych territorij (konec XVI - načalo XX v.). Samara.

FASMER, M. (1986a): Ėtymologičeskij slovar' russkogo jazyka v četyrech tomach. Tom 1 $(A-D)$. Moskva.

FASMER, M. (1986b): Ėtymologičeskij slovar' russkogo jazyka v četyrech tomach. Tom 2 ( Je-Mǔ̌). Moskva.

FASMER, M. (1986c): Ėtymologičeskij slovar' russkogo jazyka v četyrech tomach. Tom 4 (T-faščur). Moskva.

JAGAFOVA, Je. A. (2013): Ètnokul'turnoje vzaimodejstvije v Uralo-Povol'žje: opyt i sovremennyje issledovanija problemy. In: JAGAFOVA, Je. A. (red.): Problemy ètnokul'turnogo vzaimodejstvija v Uralo-Povol'žje: istorija i sovremennost'. Samara, s. 5-10.

KABYTOV,P.S. (2012): Srednjaja Volga i Zavol'žje vo vtoroj polovine XVI - načale $X X$ v.: territorial'nyje granicy, prirodno-klimatičeskije uslovija. Vestnik Samarskogo gosudarstvennogo universiteta, 2012, № 8.2 (99), s. 21-26.

KABYTOV,P.S., DUBMAN, È.L., LEONTJEVA, O.B. (2012): “Obretenije Rodiny”. Srednjaja Volga i Zavol'žje v processe razvitija rossijskoj civilizacii i gosudarstvennosti (vtoraja polovina XVI - načalo XX v.): $k$ postanovke problemy. Vestnik Samarskogo gosudarstvennogo universiteta, 2012, № 8.2 (99), s. 5-20.

KIM, I.Je. (2005): Social'nyje kačestva čeloveka i ich vyraženije v sovremennom russkom jazyke. Izvestija Ural'skogo gosudarstvennogo universiteta, 2005, № 39, s. 163-175.

LEONTJJEVA, T. V. (2012): Socioreguljacija priema pišči v zerkale russkoj dialektnoj leksiki. Jazyk i kul'tura, 2012, № 2 (18), s. 27-43.

MYZNIKOV, S. A., KUZNECOVA, O. D. (red.) (1972): Slovar' russkich narodnych govorov. Vypusk 8. Moskva-Leningrad-St.-Peterburg.

MYZNIKOV, S. A., KUZNECOVA, O. D. (red.) (1981): Slovar' russkich narodnych govorov. Vypusk 17. Moskva-Leningrad-St.-Peterburg.

TOLSTOJ, N. I. (1991): Jazyk i kul'tura (Nekotoryje problemy slavjanskoj ètnolingvistiki). In: DMITRIJEVA, O. L. (red.) i dr.: Russkij jazyk i sovremennost'. Problemy i perspektivy razvitija rusistiki. Čast' 1. Moskva, s. 5-22.

VENDINA, T. I. (2002): Slovo kak archetip kul'tury. In: SUDAKOV, G. V. (ed.): Russkaja kul'tura na rubeže vekov: Russkoje poselenije kak sociokul'turnyj fenomen. Vologda.

\section{About the author}

Tatyana Evgenyevna Bazhenova, Samara State University of Social Sciences and Education, Faculty of Philology, Department of Russian Language, Culture of Speech and Training Methodology, Samara, Russia, bazhenova@pgsga.ru 
